Full title: Perspectives on hand functioning in girls and women with Rett syndrome

Short title: Hand function in Rett syndrome

Journal: Developmental Neurorehabilitation

Authors: Jenny Downs ${ }^{1,2}$, Stephanie Parkinson ${ }^{2}$, Helen Leonard ${ }^{1}$, Pamela Diener ${ }^{3}$, Meir $\operatorname{Lotan}^{4,5}$

Affiliations:

${ }^{1}$ Telethon Institute for Child Health Research, Centre for Child Health Research, University of Western Australia, Perth, Western Australia

${ }^{2}$ School of Physiotherapy and Curtin Health Innovation Research Institute, Perth, Western

Australia

${ }^{3}$ School of Health Professions, Marymount University, Arlington, VA, USA and School of Medicine, Georgetown University, Washington, DC, USA

${ }^{4}$ Israeli Rett Center, National Evaluation Team, Chaim Sheba Medical Center, Tel HaShomer, Ramat Gan, ${ }^{5}$ Department of Physical Therapy, University Center of Judea and Samaria, Ariel, Israel.

Address correspondence to:

Dr Jenny Downs

PO Box 855,

West Perth, 6842

Australia

Tel 61-0894897777

Fax 61-0894897700

Email: jdowns@ichr.uwa.edu.au

Declarations: There are no potential conflicts of interest or commercial support for the authors.

\title{
Acknowledgements:
}

The authors acknowledge their extremely valuable and rewarding clinical experiences from working with those affected by Rett syndrome. The Australian Rett Syndrome program has been funded by the National Institutes of Health (5R01HD043100-05) and also the National Medical and Health Research Council (NHMRC) project grant \#303189 for certain clinical aspects. 


\section{Abstract (175/250)}

Introduction: Rett syndrome is a rare neurodevelopmental disorder that affects mainly girls. After relatively normal early development, there is a period of developmental regression during which hand function is lost. Hand function is affected by additional impairments of dyspraxia and hand stereotypies.

Methods: We conducted a review of hand function and stereotypies in Rett syndrome and developed a toolkit for their assessment and treatment.

Results: The current literature on the management of hand function in Rett syndrome is limited by both the number of peer-reviewed papers and sample sizes within each study. We have suggested assessment and treatment strategies based on available literature, clinical experience, and grounded in theories of motor control and motor learning.

Conclusions: Multicentre studies are needed to better determine the evidence base for treatments. In the meantime, clinical needs can be addressed by supplementing the evidence base with an understanding of the complexities of Rett syndrome, theories of motor control and motor learning, information from environmental enrichment studies conducted on animals, and clinical experience from working with other similarly affected populations.

Keywords: Rett syndrome, $M E C P 2$, hand function, stereotypies 


\section{Introduction}

Rett syndrome is a neurodevelopmental disorder usually associated with a pathogenic mutation in the MECP2 gene. ${ }^{1}$ The early descriptions of Rett syndrome ${ }^{2}$ highlighted altered hand movements and function which are now recognised as central to the syndrome. There is generally normal early development followed by a period of developmental regression at around 6 to 30 months. At the time of regression, the signs of Rett syndrome develop, including loss of hand function and communication skills and the development of hand stereotypies and impaired gait. ${ }^{3}$ Those affected have considerable difficulties in performing functional daily activities, particularly in relation to communication, ${ }^{4}$ gross motorskills ${ }^{5}$ and hand function. ${ }^{6}$ Co-morbidities include poor growth, ${ }^{7}$ breathing abnormalities, ${ }^{8}$ scoliosis ${ }^{9}$, epilepsy ${ }^{10}$ and sleep difficulties. ${ }^{11}$ Overall, the clinical presentation is severe in terms of both functional impairment and associated medical problems.

The MECP2 gene is located on the $\mathrm{X}$ chromosome and therefore the disorder mainly affects females and is responsible for the production of the MeCP2 protein, a methylated DNA binding protein with abundant expression throughout the central nervous system. The MeCP2 protein is first expressed in the brainstem and thalamus before being expressed more rostrally throughout brain development. ${ }^{12}$ More than 200 specific pathogenic mutations in the MECP2 gene have been described ${ }^{13}$ with eight of these occurring commonly. Large cross sectional and population-based studies have shown relationships between the specific mutation and phenotype. Those with mutations p.R168X, p.R255X or p.R270X often manifest a relatively severe phenotypic expression ${ }^{14,15}$ while those with mutations p.R133C p.R294X, p.R306C or a C-terminal deletion are milder in comparison, ${ }^{14-16}$ with greater likelihood of walking and having better hand function skills. 
The purpose of this paper is to review features of Rett syndrome that relate to hand use. Specifically, we will describe the influences of the motor impairments of dyspraxia and hand stereotypies on hand function. Using the frameworks of motor control and motor learning theories, we will discuss current perspectives on assessment and management.

\section{Hand function}

\section{Functional abilities}

The loss of purposeful hand skills during the period of regression is a prominent feature. Abilities to grasp objects were assessed using video-taped footage in 144 girls and women who were participating in the population-based Australian Rett Syndrome Study and were presented with a range of objects including a ball, bottle, spoon, toy and small pieces of food. ${ }^{6}$ Only $30 \%$ were unable to grasp any of the objects, a further $17 \%$ could hold an object once it had been placed in their hand, and approximately 12\% were able grasp and continue to hold a large object using cylindrical or spherical grasping (eg hold a spoon or small ball). The remainder (40.3\%) had finer grasping skills and could grasp, pick up and hold a small object such as a piece of food, approximately one quarter with a raking grasp and three quarters using the radial side of the hand. Of those using the radial side of the hand to pick up small objects, slightly less than half were able to transfer an object from hand to hand. ${ }^{6}$ Hand function skills appeared to be influenced by age and genotype. Those with the p.R168X or p.R270X mutation generally had the poorest hand function whilst those with the p.R133C, p.R294X or p.R306C mutation generally had better hand function, consistent with patterns found in large genotype phenotype studies. ${ }^{14,15}$ Consistent with the idea that functional skills in general are poorer with increasing age, ${ }^{17}$ those who are older appeared also to have the poorest hand function although the magnitude of difference between different age-groups was generally small. ${ }^{6}$ 
Video of hand function after three to four years was observed in a sub-sample of 72 of the 144 girls and women who participating in the initial Australian Rett syndrome video study. Several gained skills, $60 \%$ maintained their skill level and in approximately $40 \%$, skills declined slightly, indicating relative stability of function over this time frame. ${ }^{18}$ Additional research confirms the general stability of hand function over time, reflected mainly in reports of self-feeding activities. A cross-sectional survey in Sweden $(n=121)$ cases found that many girls and women maintained self-feeding skills, and that a few regained lost feeding abilities with training (3/46) or were taught how to self-feed (2/38). ${ }^{19}$ Along with reported studies, ${ }^{20,} 21$ our clinical experience also suggests that training and practice can assist with the development of self-feeding skills. There appears to be phenotypic variability in the longitudinal course of hand function, influenced in some cases by opportunities and practice.

The ability to press a switch to operate a toy or educative device is often possible when grasping skills are poor. ${ }^{22}$ We have also observed that "usual" abilities can also be remarkably improved when the girl or woman with RTT is presented with a powerful motivating incentive. For example, a girl presenting with very poor abilities to hold and manipulate objects was able to pick up a glass of Cola from the table, press it against her lips, holding it steadily whilst drinking the contents until the glass was completely empty: but only when the glass was filled with Cola. Dystonic hand postures can also preclude hand function and these postures have been observed more frequently with increasing age. ${ }^{23,24}$

\section{Dyspraxia}

The concept of praxis is the ability to gesture and use tools, ${ }^{25}$ and a lack of or decrease in these abilities is termed apraxia or dyspraxia, respectively. Dyspraxia is typically described in 
the adult literature in relation to acquired brain injury and diagnosis depends on the exclusion of other causes of motor dysfunction such as muscle weakness, abnormal tone or posture, movement disorders such as tremor or chorea as well as communication or cognitive impairment. Dyspraxia is assessed by a delay in or absence of motor response to a verbal command (with the above proviso), inability to imitate and reproduce symbolic (eg waving) and non-symbolic (eg vertical palm position) movements and/or inability to use or manipulate an object. Errors in one or more of timing, sequencing, spatial responses, perseveration and unrelated responses can occur. ${ }^{26}$ Classically, ideomotor dyspraxia is defined as difficulty imitating gestures or performing motor tasks on command, and ideational dyspraxia as difficulty using objects such as eating utensils or a toothbrush because the task is not understood. ${ }^{27}$ The paediatric literature often describes dyspraxia in relation to developmental co-ordination disorder in which many of the children have delayed development of praxis without neurological explanation. ${ }^{27}$ Dyspraxia is considered an important contributor to motor difficulties in Rett syndrome although also there are cooccurring neurological impairments that can provide some explanation for motor difficulties. ${ }^{17}$ There is much information to be processed prior to the performance of a planned or goal directed motor task. For example, there is prerequisite thinking in relation to perception of the task at hand, recall of previous experiences in relation to that task, and then planning as to how the task will be achieved. Alterations in the processing of information at these stages could conceivably form the basis for dyspraxia in Rett syndrome.

Our understanding of the neural and cognitive systems that underlie human praxis is still not well established but a recent phenomenological study of six patients with stroke and dyspraxia has articulated their experiences. ${ }^{28}$ During interviews, the patients described gaps between their intention and ability to perform an action, an awareness that their actions were 
fragmented and perceptions of unusual movements. They also described feelings that their intentionality was "on the loose" and that they were fighting against tools when trying to use them. ${ }^{28}$ Such investigation has not been possible in RTT because of communication difficulties and presumed cognitive impairment but these experiences provide insight. Dyspraxia makes it difficult to convert an intention into action and observations that many girls and women spend considerable time watching an object before grasping and picking it up have been documented. ${ }^{29}$ In contrast, automatic and more spontaneous hand movements such as scratching or rubbing eyes are performed with much greater ease. ${ }^{30}$

\section{Hand stereotypies}

Stereotypies are involuntary, repetitive and seemingly meaningless movements. ${ }^{31}$ and are a hallmark characteristic of Rett syndrome. These movements may include joined-hand movements such as wringing/clasping, clapping or mouthing; or single-hand movements such as mouthing, clasping or tapping ${ }^{32,33}$ although the most common hand stereotypy is a midline wringing action. Whilst stereotypies usually co-occur with other activities of daily living or may include manipulation of an object, they can be extremely compelling and restrict hand function or may be so excessive that they become self-injurious, such as excessive rubbing of the skin on the hands, biting or chewing of hands, or hand to head banging. ${ }^{34}$

\section{Motor control and motor learning}

The theories of motor control and motor learning can provide a framework to usefully inform the assessment and management of hand function in Rett syndrome. Motor control is the ability to regulate or direct the mechanisms essential to movement such as generation and coordination of the actions of multiple joints and muscles that produce functional movements. Motor control can be considered as an expression of the Body Structure and Function 
component of the International Classification of Functioning, Disability and Health. ${ }^{35}$ Purposeful movements (for Activities) arise from a co-operative effort of multiple neurological and musculoskeletal structures and processes, including those related to perception, cognition, planning, and the performance of the movement itself. ${ }^{36}$ Modern theories of motor control recognise the dynamic interplay of factors that together influence how movements are generated including factors relating to the individual, the environment and the task itself. ${ }^{36}$ Therefore, task performance can be analysed by considering the interactions of perceptions, recall and planning as well as the components of the movement.

Motor learning theory is concerned with how new movements are learned and old movements are modified, and involves strategies relating to the training of perceptual, cognitive and action processes. The learning of functional abilities relates not only to the performance of movement but to the application of motor skills to specific tasks within specific environments in the context of that individual's ability to perceive, recall, plan and perform. ${ }^{37}$ Factors that can optimise motor learning include opportunities for practice, intrinsic feedback from the performance and achievement of a task, extrinsic feedback in the form of encouragement and praise throughout and following completion of the task, judicious use of rest periods to avoid fatigue, performance of the task in novel conditions and in those that match the practice environment to the actual environment. ${ }^{36,38}$ These concepts have not been tested formally as strategies to enhance motor performance in individuals with Rett syndrome. However, MECP2 null mice housed in an enriched environment providing space and opportunities to practice a range of activities have demonstrated improved motor abilities, possibly associated with increased levels of BDNF and/or the reinforcement of neural synapses. ${ }^{39-41}$

\section{Assessment of hand stereotypies and hand function}


The therapist needs to perform neurological and musculoskeletal assessment for the assessment of stereotypies and hand function in Rett syndrome and Table 1 lists key stem questions and sample probing questions. Assessment depends heavily on observation with hand function best observed in functional settings. There is a need to create a relaxed and a motivating environment, and provide adequate time to allow skills to be demonstrated, taking into account the influences of dyspraxia. Careful observation of posture and trunk control, whole upper limb position as well as hand postures, whole upper limb postures as well as methods of sitting and trunk control are needed. After suggesting an appropriate motivational goal, abilities to press a switch to operate a toy or computer, use gross and pincer grasps to manipulate objects, as well as use of utensils for eating and drinking and abilities to finger feed, should be observed. If a task cannot be completed independently and after enough time is given for the girl or woman to react to the clinician request, assessment of how much participation can occur with the provision of assistance is needed. Other factors that affect performance such as motivating activities, existing structure of daily routines, changes in medication, emotional state of the child and duration of sleep at the night prior to the evaluation need also to be taken into account. The extent to which reduced range of joint movement, altered muscle tone and/or dystonia influence motor skills can be assessed by passively moving the girl or woman’s upper limb joints.

There are few measures of hand function specific to Rett syndrome with most in the literature being relatively blunt. For example, "hand clumsiness" is coded on a 5-point scale in the Rett Syndrome Motor-Behavioral Assessment. ${ }^{23}$ Based on observation, a more sensitive measure of abilities to grasp objects has been developed comprising eight levels that are sequential in complexity ranging from no grasping abilities to the picking up of small objects. ${ }^{6}$ This eightpoint scale allows greater characterization of the ability to grasp and can be used to 
complement the above assessment strategies. Whilst there are many measures of dyspraxia available in the literature, ${ }^{42}$ none are suited to the unique clinical presentation of Rett syndrome and an understanding of influences of dyspraxia is derived from the overall hand function assessment. Assessment in Rett syndrome is complicated by poor expressive communication skills and cognitive impairment, although eye gaze can be used effectively to indicate a request or choice and for social interactions. ${ }^{4}$. Whilst expressive communication skills are limited, abilities to comprehend are greater and skills of eye gaze can be used for communication and the building of rapport for successful management.

\section{Management of hand stereotypies and hand function}

Hand stereotypies are mostly left alone but there are cases where measures are needed to restrict the movement to improve function or prevent damage to the individual. If hand stereotypies are intense and interfere with hand function, socialisation or other functional abilities such as eating or independent walking, or if there is self-injury/tissue damage, strategies to restrict their action can be tried. The literature describes use of splints in small numbers of subjects. For example, use of hand splints was associated with improved selffeeding skills in two subjects, ${ }^{43,44}$ and elbow splints with reduced hand stereotypy behaviours and greater participation with existing levels of hand function in one subject. ${ }^{45}$ If needed, such strategies are utilised by mostly using soft and comfortable materials and only for necessary periods of time, rather than lengthy parts of the day. (Figure 1)

The literature for treatment is extremely limited but there is some evidence to show that abilities can improve with intervention. For example, participation by one 11 year old child in a an eight-week course of structured hydrotherapy sessions was associated with increased hand and feeding skills, and decreased hand stereotypies, hyperactivity and anxiety. ${ }^{46} \mathrm{~A}$ 
multiple baseline single case design study was conducted with five girls and women ranging in age from three to 23 years to assess the effects of a self-feeding training program. Following a four-week baseline period, intervention was implemented over five to eight weeks at each meal comprising self-spoon feeding skills with verbal prompting, demonstration and assistance as required and reinforcement. Gains included increased frequency of scooping food, spoon to mouth and spoon in mouth and these skills improved or were maintained in four of the girls at 12 month follow up. There was no record of whether the improvement in self-feeding generalised into overall hand usage. ${ }^{21}$ In a retrospective case study of the motor behaviour of a woman with RTT who died at age 60 years, introduction of supported self feeding facilitation at the age of 52 for each meal over four years led to development of self feeding skills. ${ }^{20}$ In a case study of a three year old girl receiving additional approximately weekly switch and adaptive toy use training (14 minute sessions) across a one year period, new purposeful hand use developed where there had been none. ${ }^{22}$ Grasping skills did not improve in three preschool girls with Rett syndrome following 15 months of conductive education characterised by strong support for functional use of hands, although at this young age, their hand function skills could still have been regressing. ${ }^{47}$ Whilst there is some evidence that active therapy programs can contribute to improved functional abilities, each of these studies has been conducted with extremely small sample sizes and without a control group. There is a desperate need for research to provide higher level evidence of what strategies are useful for those with Rett syndrome. Nevertheless, the potential for responsiveness to opportunities for movement and practice has been demonstrated, often with programs characterised by persistence over time. As with any evidence-based practice, clinical experience and judgement as well as the wants and needs of those affected by Rett syndrome ${ }^{48}$ will contribute to the determination of the daily routines and activities that can be implemented to promote better hand use.(Figure 2) 


\section{Concluding comments}

There are difficulties in general associated with understanding the effectiveness of therapies for rare disorders, of which Rett syndrome is one of many. Hand function is particularly affected in Rett syndrome but the current literature on its management is limited by both the small number of peer-reviewed papers and the sample size within each study. Further studies are clearly needed. In the meantime, the girls and women have clinical needs and evidencebased practice is still possible. Evidence-based practice comprises use of the best available evidence together with the clinical experience of the practitioner and the needs and wants of those affected by Rett syndrome. ${ }^{48}$ Therapists must therefore supplement available evidence with an understanding of the complexities of Rett syndrome and draw from the theories of motor control and motor learning, and from animal environmental enrichment studies. This paper illustrates a framework for evidence based practice to the management of hand functioning in Rett syndrome. 
Table 1: Suggested stem and leaf questions for assessing hand stereotypies and hand function in Rett syndrome

\begin{tabular}{|c|c|c|}
\hline & Stem questions & Leaf questions \\
\hline \multirow{12}{*}{$\begin{array}{l}\text { Hand } \\
\text { stereotypies }\end{array}$} & What types of movements are & Do they involve both hands together or one hand? \\
\hline & occurring? & Is there one or are there multiple types of stereotypies? \\
\hline & When are they occurring? & $\begin{array}{l}\text { Do they continue when the girl or woman is tired or } \\
\text { sleepy or relaxed? Or just present when she is wide } \\
\text { awake? }\end{array}$ \\
\hline & & $\begin{array}{l}\text { Are they more prevalent at the beginning of the day } \\
\text { then at the end? }\end{array}$ \\
\hline & & Do they increase when in crowded or unfamiliar places? \\
\hline & & $\begin{array}{l}\text { Does the stereotypy change when she is engaged in } \\
\text { watching television, listening to a book or music? Or } \\
\text { when hungry or thirsty? }\end{array}$ \\
\hline & How frequently do they occur? & $\begin{array}{l}\text { Do they occur rarely in the day, frequently or do they } \\
\text { occur constantly? }\end{array}$ \\
\hline & What causes them to change? & How are the stereotypies discontinued? \\
\hline & & Can they be stopped to allow for use of hands? \\
\hline & & Does anxiety increase the frequency of stereotypies? \\
\hline & Are they causing adverse effects? & $\begin{array}{l}\text { Do the stereotypies preclude use of hands to perform } \\
\text { tasks or can they be volitionally discontinued to allow } \\
\text { hand function? }\end{array}$ \\
\hline & & Are stereotypies self-injurious causing skin damage? \\
\hline \multirow[t]{17}{*}{ Hand function } & $\begin{array}{l}\text { What neurological and } \\
\text { orthopaedic factors could }\end{array}$ & $\begin{array}{l}\text { What is the muscle tone of the trunk and of the shoulder } \\
\text { girdle? }\end{array}$ \\
\hline & influence hand function? & $\begin{array}{l}\text { Is there a scoliosis that might influence posture in a } \\
\text { seating } \backslash \text { standing positions? }\end{array}$ \\
\hline & & $\begin{array}{l}\text { Is she able to ambulate independently from one place to } \\
\text { another? }\end{array}$ \\
\hline & \multirow{10}{*}{$\begin{array}{l}\text { What can the girl or woman } \\
\text { achieve with her hands? }\end{array}$} & Is she able to reach for and press a switch? \\
\hline & & $\begin{array}{l}\text { Is she able to hold objects in her hands? What are the } \\
\text { size, shape and texture of those objects? }\end{array}$ \\
\hline & & How long can she hold an object in her hands? \\
\hline & & $\begin{array}{l}\text { Can she independently release a held object from her } \\
\text { hand? }\end{array}$ \\
\hline & & $\begin{array}{l}\text { If an object (a spoon for example) is held in her hand, } \\
\text { can she bring it to her mouth? }\end{array}$ \\
\hline & & $\begin{array}{l}\text { Can she manipulate different objects (move, push, hit, } \\
\text { or transfer from hand to hand)? }\end{array}$ \\
\hline & & $\begin{array}{l}\text { Are there some functional abilities that are performed } \\
\text { better than others? }\end{array}$ \\
\hline & & $\begin{array}{l}\text { How long is her reaction time in a task requiring manual } \\
\text { function? }\end{array}$ \\
\hline & & Can she cross midline? \\
\hline & & $\begin{array}{l}\text { Can she separate her hands and can she function with } \\
\text { each one separately or activate both hands as one unit? }\end{array}$ \\
\hline & \multirow{4}{*}{$\begin{array}{l}\text { What manual activities are } \\
\text { motivating? } \\
\text { Does the environment support } \\
\text { optimal hand function? }\end{array}$} & Can hand function skills be practiced at mealtimes? \\
\hline & & What educational and play activities are engaging? \\
\hline & & $\begin{array}{l}\text { Are there a variety of activities that are enriching and } \\
\text { challenging to learn more skills? }\end{array}$ \\
\hline & & $\begin{array}{l}\text { Do support persons work together to create an enriching } \\
\text { environment? }\end{array}$ \\
\hline
\end{tabular}


Figure 1: Algorithm and toolkit for the management of hand stereotypies

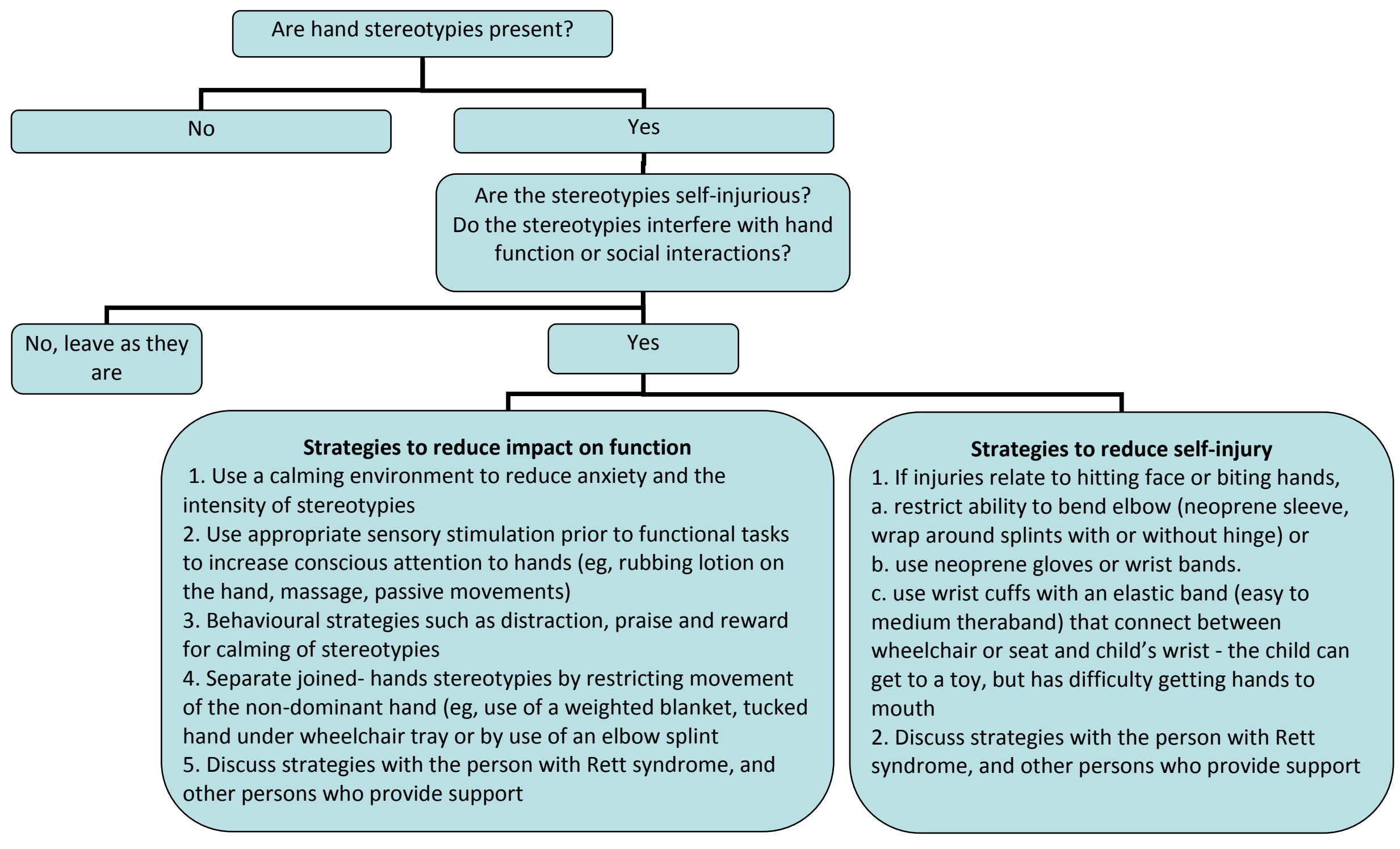


Figure 2: Using motor learning theory as a model for designing therapy strategies to improve hand function

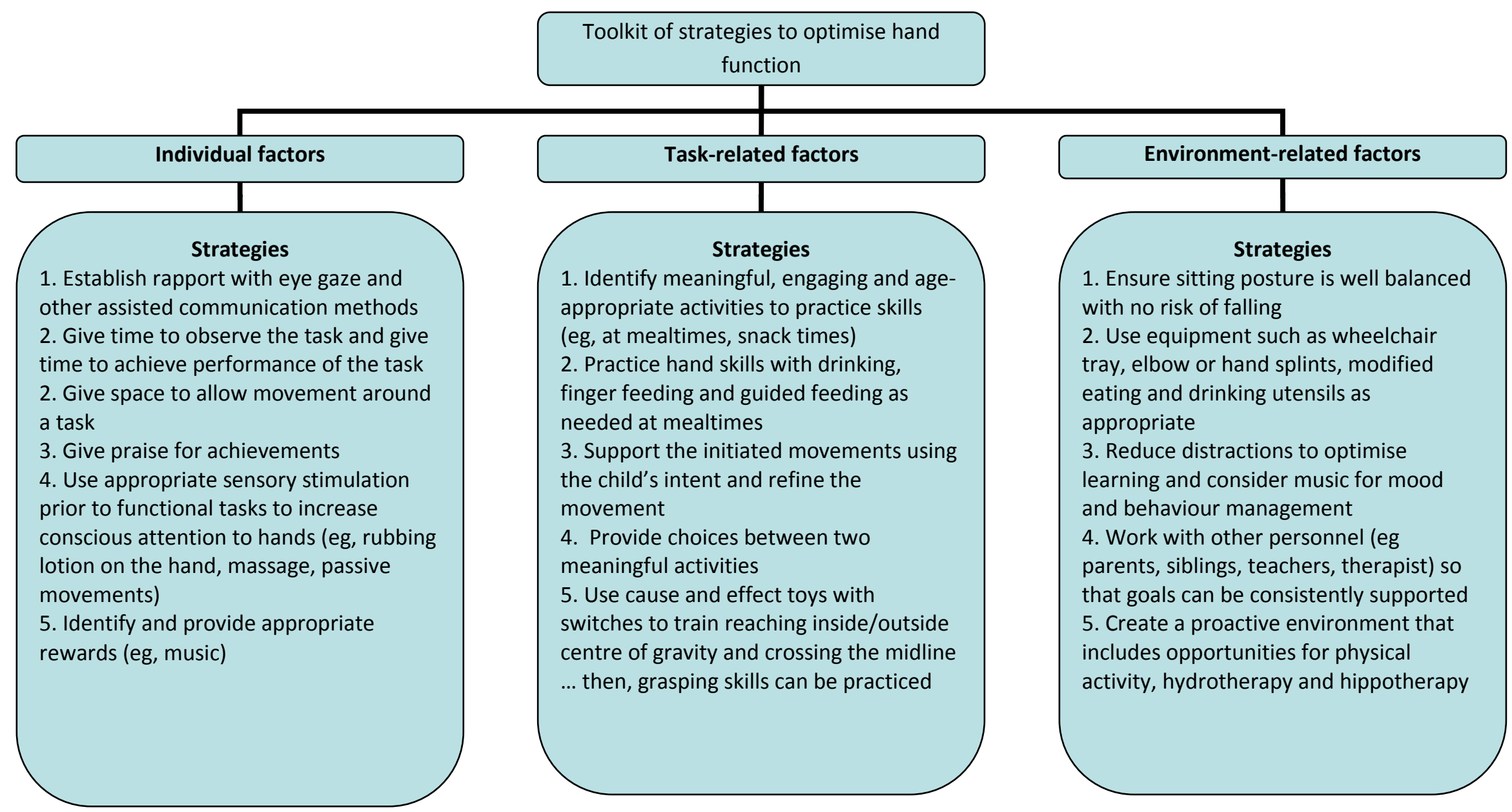




\section{REFERENCES}

1. Amir RE, Van den Veyver IB, Wan M, Tran CQ, Francke U, Zoghbi HY. Rett syndrome is caused by mutations in X-linked MECP2, encoding methylCpG-binding protein 2. Nat Genet. 1999;23(2):185-8.

2. Hagberg BA. Rett syndrome: clinical peculiarities, diagnostic approach, and possible cause. Pediatr Neurol. 1989 Mar-Apr;5(2):75-83.

3. Neul JL, Kaufmann WE, Glaze DG, Christodoulou J, Clarke AJ, Bahi-Buisson N, et al. Rett syndrome: Revised diagnostic criteria and nomenclature. Ann Neurol. 2010;68:944-50.

4. Didden R, Korzilius H, Smeets E, Green V, Lang R, Lancioni G, et al. Communication in Individuals with Rett Syndrome: an Assessment of Forms and Functions. Journal of developmental and physical disabilities. 2010;22(2):105-18.

5. Downs JA, Bebbington A, Jacoby P, Msall ME, Mcllroy O, Fyfe S, et al. Gross motor profile in Rett syndrome as determined by video analysis. Neuropediatrics. 2008 Aug;39(4):205-10.

6. Downs J, Bebbington A, Jacoby P, Williams A-M, Ghosh S, Kaufmann W, et al. Level of purposeful hand function as a marker of clinical severity in Rett syndrome. Dev Med Child Neurol. 2010;52(9):817-23.

7. Oddy WH, Webb KG, Baikie G, Thompson SM, Reilly S, Fyfe SD, et al. Feeding experiences and growth status in a Rett syndrome population. J Pediatr Gastroenterol Nutr. 2007 Nov;45(5):582-90.

8. Julu PO, Engerstrom IW, Hansen S, Apartopoulos F, Engerstrom B, Pini G, et al. Cardiorespiratory challenges in Rett's syndrome. Lancet. 2008 Jun 14;371(9629):1981-3.

9. Ager S, Fyfe S, Christodoulou J, Jacoby P, Schmitt L, Leonard H. Predictors of scoliosis in Rett syndrome. J Child Neurol. 2006;21(9):809-13.

10. Jian L, Nagarajan L, de Klerk N, Ravine D, Christodoulou J, Leonard H. Seizures in Rett syndrome: an overview from a one-year calendar study. Eur J Paediatr Neurol. 2007 Sep;11(5):310-7.

11. Young D, Nagarajan L, de Klerk N, Jacoby P, Ellaway C, Leonard H. Sleep problems in Rett syndrome. Brain Dev. 2007 Nov;29(10):609-16.

12. Samaco RC, Neul JL. Complexities of Rett Syndrome and MeCP2. J Neurosci. 2011 Jun;31(22):7951-9.

13. Christodoulou J, Grimm A, Maher T, Bennetts B. RettBASE: The IRSA MECP2 variation database-a new mutation database in evolution. Hum Mutat. 2003;21(5):466-72.

14. Bebbington A, Anderson A, Ravine D, Fyfe S, Pineda M, de Klerk N, et al. Investigating genotype-phenotype relationships in Rett syndrome using an international data set. Neurology. 2008;70(11):868-75.

15. Neul JL, Fang P, Barrish J, Lane J, Caeg EB, Smith EO, et al. Specific mutations in methyl-CpG-binding protein 2 confer different severity in Rett syndrome. Neurology. 2008;70(16 Part 1):1313-21.

16. Bebbington A, Percy A, Christodoulou J, Ravine D, Ho G, Jacoby P, et al. Updating the profile of C-terminal MECP2 deletions in Rett syndrome. J Med Genet. 2010 Apr;47(4):242-8.

17. Hagberg B. Clinical manifestations and stages of Rett syndrome. Ment Retard Dev Disabil Res Rev. 2002;8(2):61-5.

18. Downs J, Bebbington A, Kaufmann W, Leonard H. Longitudinal hand function in Rett syndrome. J Child Neurol. 2011;26(3):334-40.

19. Larsson G, Lindstrom B, Engerstrom IW. Rett syndrome from a family perspective: The Swedish Rett Center survey. Brain Dev. 2005 Nov;27 Suppl 1:S14-S9 
Jacobsen C, Viken A, Von Tetzchner S. Rett syndrome and ageing: a case study. Disabil Rehabil. 2001 Feb-Mar;23(3-4):160-6.

21. Piazza CC, Anderson C, Fisher W. Teaching self-feeding skills to patients with Rett syndrome. Dev Med Child Neurol. 1993;35(11):991-6.

22. Sullivan MW, Laverick DH, Lewis M. BRIEF REPORT - FOSTERING ENVIRONMENTAL-CONTROL IN A YOUNG-CHILD WITH RETT-SYNDROME - A CASE-

STUDY. J Autism Dev Disord. 1995 Apr;25(2):215-21.

23. FitzGerald PM, Jankovic J, Percy AK. Rett syndrome and associated movement disorders. Mov Disord. 1990;5(3):195-202.

24. Temudo T, Ramos E, Dias K, Barbot C, Vieira J, Moreira A, et al. Movement disorders in Rett syndrome: an analysis of 60 patients with detected MECP2 mutation and correlation with mutation type. Mov Disord. 2008;23(10):1384-90.

25. Dewey D. Praxis and sequencing skills in children with sensorimotor dysfunction. Developmental neuropsychology. $1991 ; 7(2): 197-206$.

26. Zadikoff C, Lang AE. Apraxia in movement disorders. Brain. 2005 Jul;128(Pt 7):1480-97.

27. O'Hare A, Gorzkowska J, Elton R. Development of an instrument to measure manual praxis. Dev Med Child Neurol. 1999 Sep;41(9):597-607.

28. Arntzen C, Elstad I. The bodily experience of apraxia in everyday activities: a phenomenological study. Disabil Rehabil. 2012 May 26.

29. Mount RH, Charman T, Hastings RP, Reilly S, Cass H. The Rett Syndrome Behaviour Questionnaire (RSBQ): refining the behavioural phenotype of Rett syndrome. J Child Psychol Psychiatry. 2002 Nov;43(8):1099-110.

30. Umansky R, Watson JS, Colvin L, Fyfe S, Leonard S, de Klerk N, et al. Hand preference, extent of laterality, and functional hand use in Rett syndrome. J Child Neurol. 2003 Jul;18(7):481-7.

31. Jankovic J. Stereotypies in autistic and other childhood disorders. In: Fernandez-Alvarez E, Arzimanoglou A, Tolosa E, editors. Paediatric Movement Disorders: Progress in Understanding. Montrouge: John Libbey Eurotext; 2005.

32. Carter P, Downs J, Bebbington A, Williams S, Jacoby P, Kaufmann WE, et al. Stereotypical hand movements in 144 subjects with Rett syndrome from the population-based Australian database. Mov Disord. 2010 Feb 15;25(3):282-8.

33. Temudo T, Oliveira P, Santos M, Dias K, Vieira J, Moreira A, et al. Stereotypies in Rett syndrome: analysis of 83 patients with and without detected MECP2 mutations. Neurology. 2007;68(15):1183-7.

34. Mount RH, Hastings RP, Reilly S, Cass H, Charman T. Behavioural and emotional features in Rett syndrome. Disabil Rehabil. 2001;23(3/4):129-38.

35. World Health Organization. International Classification of Functioning, Disability and Health: ICF. Geneva: World Health Organisation; 2001.

36. Shumway-Cook A, Woollacott MH. Motor Control: Translating Research into Clinical Practice. 3rd ed. Philadelphia: Lippincott Williams \& Wilkins; 2007.

37. Nott MT, Chapparo C, Heard R. Reliability of the Perceive, Recall, Plan and Perform System of Task Analysis: a criterion-referenced assessment. Australian Occupational Therapy Journal. 2009;56(5):307-14.

38. Gorman S. Contemporary issues and theories of motor control, otor learning, and neuroplasticity: Assessment of movement and posture. In: Umphred D, editor. Neurological Rehabilitation. 5th ed. St Louis: Mosby Elsevier; 2007.

39. Kondo M, Gray LJ, Pelka GJ, Christodoulou J, Tam PP, Hannan AJ. Environmental enrichment ameliorates a motor coordination deficit in a mouse model of Rett syndrome - Mecp2 gene dosage effects and BDNF expression. Eur J Neurosci. 2008;27:3342-50.

40. Nag N, Moriuchi J, Peitzman CGK, Ward B, Kolodny N, Berger-Sweeney J. Environmental enrichment alters locomotor behaviour and ventricular volume in Mecp2 1lox mice. Behav Brain Res. 2009;196(1):44-8. 
41. Megra M, Diener PS. Testing efficacy of sensory motor enrichment in ameliorating symptoms of Rett syndrome. Yale Review of Undergraduate Research in Psychology. in press;4.

42. Dovern A, Fink GR, Weiss PH. Diagnosis and treatment of upper limb apraxia. J Neurol. 2012 Jul;259(7):1269-83.

43. Kubas ES. Use of splints to develop hand skills in a woman with Rett syndrome. Am J Occup Ther. 1992;46(4):364-8.

44. Naganuma GM, Billingsley FF. Effect of hand splints on stereotypic hand behavior of three girls with Rett syndrome. Phys Ther. 1988;68(5):664-71.

45. Sharpe PA, Ottenbacher KJ. Use of an elbow restraint to improve finger-feeding skills in a child with Rett syndrome. Am J Occup Ther.

1990;44(4):328-32.

46. Bumin G, Uyanik M, Yilmaz I, Kayihan H, Topçu M. Hydrotherapy for Rett syndrome. Journal of Rehabilitation Medicine. 2003;35(1):44-5.

47. Lotan M, Schenker R, Wine J, Downs J. The conductive environment enhances gross motor function of girls with Rett syndrome. A pilot study. Developmental neurorehabilitation. 2012;15(1):19-25.

48. $\quad$ Straus SE, Sackett DL. Using research findings in clinical practice. BMJ British medical journal. 1998;317(7154):339-42. 